cease troubling ourselves with millions of useless observations to be added to millions already existing? No. It is an honest effort, and granting that there is surplusage of certain data, the chart is still worth while. Besides, there are some by-products of great value. To illustrate, a strict verification of the wind shifts at San Francisco, a city where the lower aircirculation is marked, might show a high percentage; but this would not be a fair test of the worth of the weather chart. Rather, some by-product, as that of frost protection. In the first week of January, I9I3, the general forecaster warned the orange-growers 480 miles away of impending trouble. Each community was warned not once, but day after day, and night after night. Fruit worth $10,000,000$. was in jeopardy. Haif was saved because of ample, accurate warnings coupled with improved methods of heating, covering, and protecting. Overtopping the vast saving, was the demonstration that protection was effective. The story of the campaign against frost extending over a period of sixteen years and culminating in the struggle of January, $\mathrm{I}_{9} \mathrm{I} 3$, is one of the most inspiring chapters in the history of horticulture. The forecaster not only gave warning, but developed the principles of protection. At least five basic patents for covering, heating, and mixing the air were obtained and donated to the public.

Again, a certain railroad system of the west coast in competition with all steam railroads of the United States was awarded the Harriman Memorial safety medal. In five years not a single passenger's life has been lost through collision or derailment of trains in a total equivalent movement of $8,000,000,000$ passengers one mile. What has this to do with the weather chart? Only this, that during those five years at times of greatest strain, during heavy rains when road-beds wash out, and derailments most easily occur, the actual head of the whole system kept in closest touch with the weather office. Time and time again the patrols on thousands of miles of roads were doubled on the judgment of the forecaster, based on the chart.

Yet, in San Francisco, it has been known to turn out fair when rain was indicated, or some sudden drizzle from the sea mar a forecast of fair weather.

And the conjecture of De Morgan which Mr. Mallock quotes, "that Sir George Airy would not have given $2 \frac{1}{2} d$. for the chance of a meteorological theory formed by masses of observations," remains a conjecture.

Blue Hill Observatory, March I I.

\section{Alexander McAdie.}

\section{Origin of Structures on the Moon's Surface.}

The difficulty raised by the Rev. O. Fisher (Nature, February 26, p. 714) with regard to the origin of the moon by fission from the earth has been answered already in part in Sir George Darwin's own writings. The length of the day when earth and moon revolved once a day was calculated by him at first as about 5 hours, the figure used by Mr. Fisher. Afterwards, Darwin showed that taking solar tidal friction into account, this period should be reduced to something of the order of $2 \frac{1}{2}$ hours, when the two bodies would be almost in contact (see Darwin, "Scientific Papers," vol. ii., pp. 323,364 ). It may not be amiss to quote here his cautious estimate of this result:- "The whole subject is full of difficulties, and the conclusions must necessarily remain very speculative."

F. J. M. Stratton.

Gonville and Caius College, Cambridge. March 6, I9I4.

NO. 2317 , VOL. 93]

The Isothermal Layer of the Atmosphere.

IT is a commonplace observation that "truths of science, waiting to be caught," are often simultaneously and independently "caught" by two or more investigators. One of the most remarkable coincidences of this kind appears never to have been definitely pointed out as such. This is the recent Gold-Humphreys (or Humphreys-Gold) explanation as to why the stratosphere is vertically isothermal; viz., because of equality in that region between emitted and absorbed radiation. This discovery is probably destined to remain conspicuous in the annals of meteorology for two reasons; first, because of its intrinsic importance, and, secondly, because of the following remarkable chronological parallelism in its independent development by two investigators :-

\section{Gold.}

Preliminary account read at the Dublin meeting of the British Association for the Advancement of Science, September $2-9$, 1908 .

Preliminary account reported in NATURE, October I, Igo8.

Final paper received by the Royal Society of London, October 5, 1908.

Final paper read before the Royal Society of London, December ro, 1908.

Final paper published in the Proceedings of the Royal Society of London, A 82, February 16, Igog.

It would be difficult to find a more interesting chronological parallel. It is particularly pleasant to add that the principals, who up to the time of the publication of their papers were strangers to each other, have since then become well acquainted and the best of personal friends.

\section{U.S. Weather Bureau, Washington, March 7 .}

\section{Unidirectional Currents within a Garbon Filament Lamp.}

DURING the past two months I have shown to some scores of people the effects described by Dr. Eve under the above heading, in Nature of March 12. His explanation of the slow creep of the displaced filaments back to their original positions does not seem to me wholly satisfactory. Other factors governing the phenomenon are the electromagnetic attractions between the current bearing loops and the plastic yielding of the heated filament. It was a search for the latter effect which first directed my attention to the other phenomena.

The negative discharge from a Wimshurst machine also alters the luminosity of the filament, and I have observed in some cases (using a modified Fleming valve), the complete stoppage of the thermionic current. These two latter effects are now being systematically investigated.

\section{F. LLOYd Hopwood}

Physics Department, St. Bartholomew's Hospital Medical College, E.C., March I7. 